Foundations of Perceptual Theory

S.C. Masin (Editor)

(c) 1993 Elsevier Science Publishers B.V. All rights reserved.

\title{
PERCEPTUAL ARTIFACTS AND PHENOMENA: GIBSON'S ROLE IN THE 20TH CENTURY
}

\author{
James E. Cutting \\ Department of Psychology \\ Cornell University, Ithaca, New York
}

\begin{abstract}
One of the most influential frameworks for the study of perception has been James J. Gibson's ecological approach. This approach is not a theory, but a metatheory, of how we perceive and understand the world around us through our senses. As a metatheory it dissolves old problems and creates new ones, fostering new ways to think about perception and creating new antinomies to ponder. This essay outlines the successes of the approach, some of its new problems, and traces some of its more and less fruitful leads.
\end{abstract}

The ancient problem of space perception became my burden. It was worrisome, for, as I gradually came to realize, nothing of any practical value was known by psychologists about the perception of motion, or of locomotion in space, or of space itself (Gibson, 1967, p. 135).

With this autobiographical statement James J. Gibson described the conundrum that faced him more than 25 years earlier, in 1941, while serving in the Aviation Psychology Program of the United States Army Air Corps. Early optimism changed to disappointment as Gibson reflected on the practical applicability of nearly 100 years of research in perception. Why?

Observers in typical perceptual experiments before (and indeed long after) Gibson's lament could not do what people do everyday. They could not explore what they saw, and they could not act directly on the basis of 
what they saw. Such experimental viewing conditions often offer no environmental background to frame the stimuli, and no visible rationale for their motion; stimuli were disembodied without earthly context. Thus, Gibson quickly learned that the results of such scientific studies were not typically useful for understanding how pilots fly aircraft. Indeed, Gibson came to doubt if they were useful for any practical perceptual task and for the next 35 years proposed that a completely new psychology of perception was necessary.

\section{"THE ANCIENT PROBLEM"}

Any "ancient problem" deserves respect. Such problems are well-worn, complex, broad, deep, and resist theoretical solution. Any contemporary theory of perception which proposes a solution to one of these will almost certainly fall well short of its goal. Rather than proposing solutions, then, Gibson proposed new ways of thinking about such problems. He created a metatheory. Not surprisingly, theoretical problems about perception remained but they were new problems, or at least new versions of old ones, and therein lay the fruitfulness of Gibson's approach.

The particular ancient problem impressed on Gibson by the war effort was the problem of "space perception" most generally, and "depth perception" in particular. Its ancient configuration suggested to Gibson that psychological experiments were not alone in failing to address practical questions about perception, space, and depth. The received tradition in philosophy elaborated from the Greeks discussed the concept of space and how it was perceived: Since the retina of any eye is locally two-dimensional and since the world around us three-dimensional, space and depth must be reconstructed from fragments of information (typically called "cues") projected on the retina. The means of reconstruction might be learned, or they might be inborn.

After grappling with it for many years, Gibson eventually found this traditional account confused and without practical merit:

Psychologists were trying to apply the theory of depth perception to the problems of aviation, especially the problem of how a flier lands an airplane. Pilots were given tests for depth perception.. The trouble was that none of these tests based on the cues for depth predicted the success or failure of a student pilot, and none of the proposals for improving depth perception by training made it any easier to learn to fly. I was deeply puzzled by this fact (Gibson, 1979, pp. 147, 148). 


\section{NOT SPACE, DEPTH, AND CUES BUT LAYOUT, SURFACES, AND THE OPTICAL ARRAY}

Gibson recognized he could not solve the problem of depth perception, so he chose not to try. Instead, he tried to dissolve it, showing its premises ill-conceived:

The notion of space of three dimensions with three axes for Cartesian coordinates was a great convenience for mathematics... but [is] an abstraction that [has] very little to do with actual perception (Gibson, 1979, p. 148).

With a penchant for linguistic analysis of terms based on their meaning in everyday usage, Gibson noted that to speak of "space perception" and "depth perception was loose talk. We do not see either space or depth. Space is an empty vessel and is invisible; thus, space itself could never be perceivable. And depth, but one mathematical dimension of space, is equally invisible and thus equally imperceivable. Rather than perceiving space or depth, according to Gibson, we perceive surfaces revealed to us by reflected light. The layout of the textures on those surfaces, their shading, and any coherent motion that may occur then specify the structure of the ground, the objects on it, and our position with respect to them.

This layout is displayed in the optical array, the spherical projection of light to a point (at which an eye might be located). Thus, except for the occasional transparent object, light coming from any local region of the optical array comes from a single object at a single depth value. That patch of light represents ambient reflection from the object's surface, which is locally two-dimensional just as the retina is two-dimensional. The local orientation of a surface is typically different than the local orientation of the retina, and the difference in orientation gives rise to texture gradients, changes in the size, shape, and orientation of markings on the surface.

This bold and new account of Gibson's, however, has not dissolved all aspects of the "ancient problem." Because most objects are opaque and because light travels in straight lines, nearer objects often interpose themselves between the observer and the reflected light from farther objects. The layout of surfaces in the optical array then shows abrupt discontinuities where the edge of a nearer object ends and the revealed surface of the farther object begins. Thus, there are abrupt discontinuities of depth in the optical array. In the traditional account of perception the existence of interposition is called the cue of occlusion; in Gibson's account it is called an "occluding edge." This is a case where terms have changed but the problem remains the same. 
How do we perceive the amount of depth between an occluding edge and an occluded edge? Motion, particularly motion generated by the movement of the observer, may provide some information. Binocular parallax may provide yet more. But more simply perhaps this problem, too, is ill-posed. Perhaps when perceiving the layout of objects in depth we don't perceive metric relations. Perhaps we only perceive depth orderwhich object is nearer than another (Gibson, 1954a; see also Todd \& Reichel, 1989). Perhaps perceiving depth is not about perceiving amounts of depth.

Space and depth versus surface layout and occluding edges are examples the new ways of thinking Gibson gave us. Theoretical discussions of space, he would claim, led to little of practical value; theoretical discussions of layout, on the other hand, were proposed in the hope they would have considerable merit. And they have. In what other perceptual domains did Gibson have influence? And where have they led us?

\section{BEYOND THE LEGACIES OF GIBSON}

Whereas Gibson's later work has profoundly shaped psychology, his earlier work did not. For example, in the field of perception it reacted to (Gibson, 1929), then provisionally accepted (Gibson \& Crooks, 1938), but finally roundly rejected (Gibson, 1951, 1971b) central aspects of Gestalt psychology. Gibson also tinkered with phenomena in other research areas, such as adaptation effects (Gibson, 1933, 1937; Bergman \& Gibson, 1959), learning theory (Gibson \& Hudson, 1935), memory research (Gibson \& Raffel, 1938), and even social psychology (Gibson, 1950a; see also Gibson, 1967; Reed, 1988).

None of these works, however, had the impact of his later perceptual research, and none of his empirical work in perception had the impact of his metatheory. Called by some "our one original, irreplaceable creative genius" (Restle, 1980, p. 291) Gibson wrote in his later years with "strange authority, merely stating his position rather than marshaling experimental evidence" (Restle, 1980, p. 291).

Gibson's "ecological approach" is best captured by a relatively small cluster of ideas. Here I will focus on five: (1) the everyday surround, (2) functionalism, (3) exploration and the interrelation of perception and action, (4) information and its adequacy for perception, and (5) the difference between the perception of pictures and of objects in the everyday surround. Each of these ideas has been fruitful; each has led to new theoretical inconsistencies with which he and his followers grappled. 


\section{THE ECOLOGICAL WORLD OF PERCEPTION: WHAT IS THE NATURE OF ITS ECOLOGY?}

\section{Control and Phenomena}

The essence of experimentation in any science is the control of independent variables in order to observe their effect on dependent variables. The essence of experimentation in perceptual psychology is the control of stimuli to observe their effects on what is perceived (see Cutting, 1991c). But such control can create a metatheoretical tension, particularly in perceptual science.

As Neisser (1976) effectively suggested, there was something odd about the stimuli typically found in the experiments of perceptual and cognitive psychology during the 30-year period after World War II, and even the period before. Control became linked with brevity. Visual stimuli in particular were so brief they came "very close to not existing at all" (Neisser, 1976, p. 35) much less being representative of the "serious business of perceiving the world" (Gibson, 1971, p. 31).

Surely, pleaded Neisser, we cannot generalize to everyday perceptual phenomena from phenomena unrepresentative of what occurs outside the laboratory. Such a plea, however, was not new. Indeed Raymond Dodge, inventor of the modern tachistoscope, made a similar statement:

I find that the tendency to reduce the physical exposure time to a minimum wherever the aim is to present an adequate exposure of the simplest kind is a methodological mistake, based on a psychophysical misconception. It introduces unusual conditions altogether foreign to the natural fixation pause and leads, or may well lead, to a distorted analysis of the processes of apprehension; making the conclusions, in so far as they are referred to normal perception, not merely valueless but false (Dodge, 1907, p. 32).

Dodge and Neisser thus warned us of a pernicious fact: Experimental control will always create perceptual phenomena. We must then always ask ourselves: Are these phenomena important? Can we be assured they are more than epiphenomena in our laboratories? If we cannot, what is their worth? Such questions are worth asking, but there is also a common retort: If we relinquish control how are we to study perception and still conduct fruitful experimental research?

\section{Ecology and Control}

Gibson offered a way to avoid the horns of this dilemma. He suggested we start not with the concept of control, but with the phenomena of everyday perception in the natural environment. This theme was present in 
his work as early as in Gibson and Crooks (1938), but is perhaps broadest and clearest in Gibson (1966) where his presentation of the capabilities of all our senses focused on the needs and tasks common to us and our forebearers. It was from this appeal that Gibson fashioned his ecological approach to perception. With the help of powerful computers to generate complex, controlled stimuli (Cutting, 1991a), this approach has proven rich and empirically rigorous.

The empirical foci of research embracing the ecological approach have focused many phenomena relatively new to the empirical study of perception: on information available when we move through the environment (e.g., Gibson, 1950b, 1958; then Lee, 1980; Warren, Morris, \& Kalish, 1988; Cutting, 1986; Cutting Springer, Braren, \& Johnson, 1992), on the perception of events (e.g., Gibson, 1966; Gibson \& Kaushall, 1973; then Cutting, 1981; Pittenger \& Shaw, 1975; Warren \& Shaw, 1985); on the perception of surfaces (e.g., Gibson, 1950c; then Cutting \& Millard, 1984; Todd \& Reichel, 1989) and the utility of their layout around us (Warren, 1984; Mark, 1987); and on manual exploration (e.g., Gibson, 1962; then Burton \& Turvey, 1990; Barac-Cikoja \& Turvey, 1991; Chan \& Turvey, 1991). All these tasks areas seem fundamental and important, they seem "ecological," and in no case has experimental control been sacrificed.

\section{Which ecology?}

The underlying appeal of Gibson is to the ecology of the perceiver. But it is a particular ecology, deeply and fundamentally biological. Gibson was most concerned about natural environments, not carpentered worlds. Perceptual errors are seen to be relatively uncommon in the natural world because of the close-knit relation between perceptual systems and the environment they evolved within. To be sure, errors are thrust upon us occasionally, but they arise typically by dint of our technology (Gibson, 1979). Our inventions, such as large panes of glass, are omnipresent and can lead to serious injury if they are not treated properly. They are new, and did not constrain our evolution. Place glass over a small chasm and, as they should, even the youngest viewers become wary (E. J. Gibson \& Walk, 1960).

The biological underpinnings of ecology in Gibson's ecological approach contrasts with an earlier idea. The ecology of Brunswik (1943, 1956), for example, is the surround of the perceiver. It is abiological, and based on personal experience molded by society. Perhaps at the end of the 1950 s, with the rise of information processing and its disinterest in context, the two ecologies seemed closely allied. Today they seem less so.

The best-known term capturing the appeal to everyday phenomena is "ecological validity." But interestingly, this phrase came from Brunswik 
(1956), to whom it was given by Lewin (see Brunswik, 1943, pp. 259 n., 267 n.). Thus, the term was not originally Gibson's although it is now wholly attributed to, and appropriated by, those who follow the ecological approach. At issue in the 1990s, however, is that Gibson $(1957,1961)$ rejected Brunswik's ecology, but many of those who espouse the ecological approach have not.

The issue at stake may be seen clearest in a comparison between Gibson (1979) and Neisser (1976). Despite similarities between these works and mutual acknowledgments by the authors, a stark contrast can be drawn. For Neisser, nothing would be more "ecological valid" than having a child sit in front of a television set; for Gibson, on the other hand, nothing would be less so. The television is an ever-present aspect of our 20 th century environment, found in most homes in Western societies; but the television is also a technological device used to present cinematic sequences or series of pictures, about which I will say more later. For Gibson (1979) pictures, moving or otherwise, are not perceived "directly;" and we did not evolve to look at television.

To be sure, evolution might be said to run in the reverse direction. There is a nontrivial sense in which televisions evolved to fit our visual systems. However, such a statement is inadequate as a solution to the problem. The geometric optics of televisions typically present to viewers not sitting directly in front of them a world which should be seen as containing no rigid objects (Cutting, 1987, 1988, 1991b). Yet, of course, rigidity is seen more or less as it is in the outside environment.

\section{Two houses}

Ecos means "house," but when discussing ecology is it the house in which we evolved or the house which we have built? Therein lies a tension between in all appeals to the "natural" world. The general character if not underlying nature of the textures, the surfaces, the spaces, and the lighting in the two "houses" is quite different. In our manufactured surround the textures are much more regular, the surfaces much more planar or more regularly curved, the spaces much more "geometric," and the lighting more local, focal, and multidirectional than in our nonurban, outdoor surround.

The problem of two (or even more) ecologies was recognized by Gibson, and recognized by those who follow the ecological approach (e.g., Michaels \& Carello, 1981). Unfortunately, it is too often and too quickly dismissed:

It is a mistake to separate the natural from the artificial as if there were two environments; artifacts have to be manufactured from natural substances. It is also a mistake to separate the cultural environment from 
the natural environment, as if there were a world of mental products distinct from the world of material objects. There is only one world, however diverse, and all animals live in it although we human animals have altered it to suit ourselves (Gibson, 1979, p. 130).

Such an answer does not suffice. The tension between the appeal to the two different "houses" lies at the foundation of perception. If biology is to rule in perception-and clearly there is a very important sense in which it must-then evolution plays the major role of selecting the properties of our perceptual systems, presumably over millennia and even larger epochs. If culture is to rule, then humankind invents and manufactures what is seen over the course of a relatively few number of years, and evolution can play no role.

To be more concrete, let me pervert Koffka's famous question in two ways (Koffka, 1935; see also Gibson, 1971b; Cutting, 1991c). First, "why do we see certain biological, geological, chemical, and meteorological things as we do?" The answer can only be that our visual systems evolved in environments containing such objects and events, and the forces of evolution played upon these systems generally selecting out the properties needed for survival.

Second, "why do we see architectural, technological, and graphical things as we do?" The answer here is much less clear. We did not evolve to see these objects. Although there must be some relation between the structure of this second class of entities and the structure of the first, that relation is unknown and certainly worthy of further study. But because this class of artifacts is "manufactured from natural substances" (Gibson, 1979 , p. 130) does not guarantee we will perceive tokens of artifactual class in the way we perceive tokens of the natural class.

Nevertheless, the appeal to nature, whether something that fashioned us or something that we fashion, has had deep an lasting impact on the field of perception. Moreover, the idea that the structure and function of visual systems are tightly fit to tasks they must do everyday has already been appropriated into other fields, particularly computer vision (Marr, 1981) in the form of "computational theories." These are theories, not of computation per se, but about what needs to be computed. Everyday tasks seem to govern the selection of such theories. Indeed, some computational theories about extracting one's movement vector during locomotion (Hildreth, 1992; Perrone, 1992) look like corresponding ecological theories (Warren et al., 1988). Thus, the ecological approach has been sufficiently fruitful that those espousing virtually no other tenets of Gibson often wind up following in his tracks. 


\section{FUNCTIONALISM, BIOLOGY, AND TECHNOLOGY: AFFORDANCES AND THEIR CREATION}

Nowhere is the conflict between biological and cultural ecologies so clear as in the study of affordances. Affordances are a useful contrivance of Gibson's, coined and modified by him from Lewin's notion of Aufforderungscharakter (Gibson, 1979, p. 138). Most simply, affordances are offerings of potential actions-picking up, grasping, shaking, eatingwhich perceivers can carry out with objects (see also Turvey, 1992). They are also the functionalist core of the ecological approach.

Affordances are readily perceived (Gibson, 1979). For example, one can readily see that a small stone is throwable and, upon hefting it, one can tell how far it might be thrown (Bingham, Schmidt, \& Rosenblum, 1989); one can see that a surface whose height is between one's knees and one's hips is sit-on-able (Mark, 1987); and one can see that a vertically uniform aperture a bit wider than one's shoulders is pass-through-able (Warren \& Whang, 1987).

But plainly one can also see that a piece of paper affords a nearly uncountable number of actions (Cutting, 1982), as I will discuss later; and that the handles on most doors afford opening, but in many modern buildings they occasionally afford only confusion and bewilderment (Norman, 1988, 1992). ${ }^{1}$ Modern technological objects are either multiply affording or they afford things that didn't exist before; indeed, one can say the driving force of invention is to increase the number of affordances around us.

There is a deep and important sense in which the concept of affordance is more applicable to artifacts than to natural kinds. Moreover, I predict that future systematic study of affordances is likely to create further rift between the two ecologies-the biological and the cultural-within the ecological approach. But such a tension only highlights the fruitfulness of the overall approach; it leads researchers and theorists to new venues with new ideas and to encounter new problems.

1 Norman's (1988, p. 219) account of the biological/cultural conflict in affordances is particularly telling:

The notion of affordance and the insights it provides originated with J. J, Gibson... 1 believe that affordances resull from the mental interpretation of things, based on our past knowledge and experience applied to our perception of things about us. My view is somewhat in conflict with the views of many Gibsonian poychologists, but this internal dehate within modera psychology is of tittle relevance here.

Thus, for Gibson affordances have a biological origin, for Norman they have a cultural one. 


\section{PERCEPTION AND ACTION: ISN'T THERE SOMETHING MORE TO PERCEPTION THAN WHAT OCCURS IN EXPLORATION?}

Another pre-eminent theme in Gibson's work concerns the relation between perception and action. In essence, according to Gibson, we perceive things which offer action, that action allows us to perceive anew, we act again, and so forth. This idea was apparent in Gibson (1950b), but systematically broached only later (Gibson, 1958) when it then became a central theme in all his later works (Gibson, 1966, 1979).

The past decade of research has shown stunning examples of the relation between perception and action. For example, based on visual information adjustments in grasping and hitting continue to be made in the last 100 msec before contact with a ball (Bootsma \& van Wieringen, 1990; Savelsberg, Whiting, \& Bootsma, 1992; see also Watts \& Bahill, 1990). There have also been examples of perceptual abilities exquisitely yoked to requirements dictated by moving through the environment (Cutting et al., 1992), and perceptual judgments seemingly dictated by rules and physics of motor production (Viviani \& Stucchi, 1992).

The coupling of certain aspects of visual perception and action is compelling. This marriage is consummated in exploration, which the ecological approach takes as its paradigm case. We perceive things of interest; we then move our heads and eyes, which changes the information available to us; we then often approach objects, bringing us new information; we then frequently grasp objects and turn them, which brings yet more information; and so forth. This is a perception-action cycle of great persuasiveness (Neisser, 1976). Each act is performed uniquely according to the situation, and the flow and sequence of perception is guided uniquely by these acts.

\section{Divorcing perception and action}

Nonetheless, to focus exclusively on where there is a tight relation between perception and action is to lose sight of many perceptual and cognitive abilities researchers ought to study. Outside the case of exploration perception-action couplings may be few, and there is quite a lot in the "serious business" of perception (Gibson, 1971, p. 31) which is not exploration.

Listening and reading, for example, are two perceptual skills with little if any need for overt action. This is true despite the fact that arguably the closest linkage between perception and motor control might be said to occur in them. Speech perception, in particular, is domain with many variants of motor theories of perception (e.g., Liberman \& Mattingly, 
1985). Nonetheless, one can learn and understand speech, and even read, without the ability to talk (Lenneberg, 1962).

Moreover, the ability to read print need not entail any action. Although the alternations of saccades and fixations during reading look like a perception/action coupling, it is clear that, if the necessity of saccades is removed by rapidly presenting strings of words in succession at the same place on a computer display, then reading becomes even faster. These saccadic acts may make normal reading possible, but they are basically only a mechanical convenience; reading is better, faster, and more engrossing when saccades are not needed. ${ }^{2}$

Moreover, the lack of perception-action coupling is not confined to language sources. For example, olfactory stimulation depends on breathing and sniffing (Halpern, 1983), but the act of sniffing is relatively stereotypic and does not differentiate what will be smelled. Similarly, although the taste of liquids is modulated by sips to keep adaptation from occurring, sips are essentially alike yet the tastes of the liquids different. In both modalities action makes perceptions occur, but the actions are not linked to specific perceptions they are only linked to perceiving of any kind. Such a linkage is not particularly compelling.

Perhaps the most important nonvisual arena for discussion of perception and action occurs with "active touch" (Gibson, 1962), later called haptic exploration (Gibson, 1966). Gibson (1962) reported that active exploration of various cookie-cutter shapes yielded identification results superior to passive exploration (having someone else move your hand over the objects). Indeed, this study has been cited as among the twenty most important experiments in the history of science (Harré, 1981). However, the superiority of active over passive touch has not universally been found (see Appelle, 1991); indeed, it may not exist when proper controls are included.

What should be clear, then, is that perception and action sometimes come together in exquisite ways. However, outside the domain of overt exploration the two do not seem to be as closely linked as Gibson would have us believe. Moreover, to study perception in the absence of action is by no means an empty pursuit. And to study perception exclusively in the context of action runs the risk of missing important aspects of sensory qualities (e.g., color, tone, taste, odor, temperature, pain), whose discussion has dominated the history of perception.

2 The technique is often called RSVP (rapid serial visual presentation). When one presents a succession of a small series of words in a story at fixation such that saccades are not needed, and give the reader control over the rate of presentation, that reader can (without practice) read faster than he or she does normally (Michael Kubovy, personal communication; see also Potter, Kroll, \& Harris, 1979). 


\section{ADEQUACY AND NUMBER OF INFORMATION SOURCES: SPECIFICATION AND INVARIANTS}

Gibson's notion of information was new; it was not Shannon and Weaver's (1949) measured in bits, and it had no relation to the number of alternative possibilities implied by the existence of an object (Garner, 1962; see also Cutting, 1986b, 1991c). Gibson's information is information about objects and events (Gibson, 1966), and in vision it is typically measured in the geometry of projections in the optical array.

Throughout his later career Gibson worked with the idea that information specified what was to be perceived. Information, according to Gibson, doesn't typically lie; all a perceiver need do for accurate perception is attend to a pertinent object or event, and pick up the appropriate information available in the optical array. This logical gambit was an important counter to Plato, Aristotle, and most subsequent thinkers. Contrary to centuries of thought, Gibson felt the perceptual senses could be trusted and relied upon. The traditional argument in philosophy-the argument from illusion (if the senses can be deceived, how do we know they do not always deceive us?)-was considered desperately wrong by Gibson. In its place he presented a new biological pragmatism-what I call the argument from evolution (if the senses were deceived too frequently, we would have surely become extinct long ago).

The trustworthiness of perception for Gibson is built upon information available to the perceiver. Since the typical variables of sensation and psychophysics yielded results that were not sufficiently trustworthy, higher-order variables were then thought to be the carriers of information. These higher-order variables were first gradients (Gibson, 1950), then invariants (e.g., Gibson, 1961), and later even complexes of invariants (Gibson, 1979). Gradients are unidimensional measures (or maps; Cutting, 1984; Stevens, 1984) taken on projections of objects or textures lying on a surface which reflect the change in their orientation with respect to a particular viewpoint; invariants are measures taken on optical projections of objects which do not change with viewpoint; invariant complexes may often turn out to be affordances.

\section{Specifiers: Many or One?}

When information is a specifier of an object or event, that information is said to predict (more or less) completely what ought to be perceived by an alert and attention-paying perceiver. But as Gibson passed from being a global psychophysicist interested in geometric projections of the world's surfaces (Gibson, 1950c, 1954a, 1959) to an ecological psychologist interested in the properties in ecological optics (Gibson, 1961, 1966, 1970), 
there was a systematic change in his outlook on the nature of information. Specification remained, but an earlier pluralism gave way to monism.

Gibson as a global psychophysicist felt the information in the world was rich and it multiply specified what to be perceived. For example:

The [psychophysical] hypothesis does not assert that there is only one variable of the energy flux with which a given phenomenal variable is in correspondence. Two or more variables of stimulation can yield the same quality of experience (Gibson, 1959, p. 466)

and

Under optimal conditions of illumination there is generally more than enough information for perception-it is redundant (Gibson, 1960a, p. 30).

Gibson as an ecological psychologist appeared to give up on this idea and promote a theory of perception in which there was only one source of information, typically a "higher-order" source, which specified each object, event, or property thereof. For example:

The specific hypothesis is that the invariant component in a transformation carries information about an object and that the variant component carries other information entirely, for example, about the relation of the perceiver to the object (Gibson, 1965, p. 68).

Note the articles and implied singularity throughout. Indeed, those following the ecological approach have generally embraced these singularities, or one-to-one mappings; one source of information is said to specify each object or event that is to be perceived (e.g., Burton \& Turvey, 1990; Stoffregen, 1990).

The major problem with the notion of one-to-one mappings between information and object/event properties is that information appears to be richer than the later Gibson would have us believe. Indeed, there are even cases where more than one invariant can be shown to exist-for a moving plane, the cross ratio of four coplanar parallel lines and the yoked velocities in optical flow-and yet an observer can be shown to use the former when a stimulus rotates and the latter when it translates (Cutting, 1986b).

Moreover, even where invariants may not exist, other simultaneously existing sources may convey differing information. In the case of texture gradients, for example, the relative size gradient and the density gradient of texture elements seem to be good sources of information about surface 
planarity but not of curvature, yet a compression (or foreshortening) gradient in the same stimulus is a good source of information about surface curvature but not of planarity (Cutting \& Millard, 1984). Thus, information-whether invariant or otherwise-is overly rich and available for observers to use at various times and occasions for various tasks.

In summary, the safest conclusion concerning specification is that information may, or it may not, specify what is to be perceived (Cutting, 1991a, 1991c). The specifying power of information depends entirely on the circumstances under which perception takes place. If the presentation of objects is degraded by the psychologist or by nature (as in extreme daytime haziness or in any nighttime viewing), measurable information may indeed not specify what is to be seen and cognition may have a heavy hand in perception; if object presentation is not degraded, then cognition may have little role, but the observer must then combine or select various sources of information prudent to the situation (Cutting, 1986b). But what is the role of invariants?

\section{Can invariants account for perception?}

The notion that perception is guided by invariants is not new. The idea that a mathematical group of displacements reveals the invariant structure of what has been displaced can be found in Helmholtz (1878, p. 384), Poincaré (1905), Cassirer (1944), and more recently in Palmer (1991) and Leyton (1992). But these earlier and later works focus on the displacements (or transformations) rather than on the invariants themselves. Gibson's contribution was his focus on invariants as they are revealed by transformations.

There have been several critiques of the concept of invariant as borrowed from mathematics and used by Gibson (e.g., Ullman, 1980; Cutting, $1986 \mathrm{~b})$. When bruted about too loosely, invariants lose power and meaning - such as when Gibson (1979, p. 271) wrote of the "invariant cat," which is apparently the higher-order information which specifies a cat. Given the potential of such broad emptiness it seems safest, then, to try to stay as close to the mathematical origins of the term as is possible, and when possible look to projective geometry for help (Cutting, 1986b). Within this stringency, however, invariants then appear to become too few to guide perception.

My own view of the global effectiveness of invariants in their ability to account for perception has changed markedly. After spending the better part of 15 years in their active search, my view is that invariants for perception exist, but they are atypical perceptual information.

$I$ have found effective invariants for the perception of human gait (Cutting, Proffitt, \& Kozlowski, 1977; Cutting, 1978a); for the perception 
of relative smoothness of rolling wheels (Proffitt, Cutting, \& Stier, 1979; Cutting \& Proffitt, 1982); for the perception of appropriate aging in a human face (Cutting, 1978b; see also Pittenger \& Shaw, 1975); for the perception of one's direction of heading during locomotion (Cutting et al., 1992); for the perception of rigid planarity (Cutting, 1986b); and I have also discussed several other invariants found by others (Cutting, 1986a). ${ }^{3}$

But the search for useful invariants has been hard work and, after quite a long period of time, the ground that has been worked appears not overly fertile. It seems likely that the number of useful invariants isolated since Gibson first espoused them (Gibson, 1950, p. 153n) probably number less than two or three dozen. Thus, although invariants worth the mathematical name do exist for perceptual systems to use, the slow pace at which they have been uncovered suggests that invariants might be relatively rare. Moreover, they are surely too few for perception to operate by invariants alone.

In summary, then, there is great utility in Gibson's concepts of information and specification for perceptual psychology. Nonetheless, the notions of one-to-one mappings and of invariants may not be a part of the same long-lived theoretical armamentarium. The search for invariants has been sufficiently fruitful to warrant continued interest in them, ${ }^{4}$ but the results of this search also warrant skepticism about their overall utility.

\section{PAPER, PICTURES, AND REALITY}

Humankind's most deeply troubling invention is the flat sheet of paper (or, more adequately, its predecessors). From the perspective of the ecological approach, the affordances of paper are legion. As I once suggested:

A piece of paper affords equally writing gibberish and sonnets; it affords writing a shopping list or a note to a colleague; it affords making a map; it affords writing nothing upon; it affords wadding up and throwing away; it affords making paper airplanes; it affords shredding, cutting into pieces...; it quite simply affords all the possible things I can do with it. My behavior is virtually unconstrained by its affordances. To be sure, it does not afford flying to Baghdad upon, but the exclusion of a

3 More recently, Niall and Macnamara (1989, 1990; Niall, 1992) have documented the perceptual nonuse of various invariants from projective geometry.

The idea of invariants has become so popular in late 20 th century visual science that it now seems possible to have a large book on invariants for machine vision barely mentioning Gibson's work or name (Mundy \& Zisserman, 1992). 
large domain of behaviors does not diminish the fact that an infinity remain (Cutting, 1982, p. 216).

For the theoretical study of perception, the most problematic aspect of paper is that marks can be made on it; these "fundamental graphic acts" (Gibson, 1979) create pictures. The problem is that although pictures lie flat on the sheet of paper and thus are two-dimensional, through the increasing craft of the artist they can be made to look like a three-dimensional world.

Most of the history of perceptual psychology has been devoted, advertently or not, to the study of static pictures presented in tachistoscopes, on sheets of paper, or on computer screens. For those who follow the ecological approach such pictures remain interesting (e.g., Rosenblum, Saldaña, \& Carello, 1993) but their perception is thought overwhelmingly nonrepresentative of our perceptions everyday. Pictures are interesting precisely because they are perceived differently than the everyday objects around us which we evolved to see (Gibson, 1979).

Gibson was continually interested in pictures throughout his career. Moreover, he had at least three different theories of picture perception (Gibson, 1954b vs Gibson, 1960b vs Gibson 1971a, 1978). The first embraced the idea of "fidelity" and, in more modern terms, would effectively try to measure the differences pixel-region-by-corresponding-optical-array-region between an image and the reality to which it corresponded. This idea has merit, but fails in the face of caricature and nonrepresentational art. The second theory kept the idea of fidelity, but concentrated on edges and contrast rather than on intensities. The original problems remained. The third embraced "formless" invariants of structure in attempt to account for pictures with and without fidelity.

\section{Restrictions on pictorial invariants}

Unfortunately, with respect to this last theory of Gibson's, it is difficult to find invariants in a medium where there can be no transformations. Gibson (1978, p. 228) acknowledged this problem but pressed on. Moreover, he claimed invariants in pictures were "weaker" but were everywhere, specifying everything seen, with no contribution of the perceiver to be made in act of perception except information pickup:

I have argued that a Rorschach blot is a picture of sorts containing not only bleeding hearts and dancing bears but dozens of other events. It is different from a regular picture in that the invariants are all mixed up together and are mutually discrepant, instead of being mutually consistent or redundant (Gibson, 1978, p. 232). 
All this seems unlikely; it is Gibson speaking with his "strange authority" (Restle, 1980, p. 291). However, there is at least one construal of notion of invariants which is appropriate to pictures.

Consider the case of a picture of a textured surface. Texture is composed of texture elements and, by definition, each texture element is more or less the same in shape, size, coloration, and so forth. If we consider the aggregation of texture elements on a surface to be identical to one another, but transformed by displacement and rotation through space while adhering to the surface, then each texture token represents a different view of the same texture type. These displacements and rotations form a group, and the invariant structure of the single texture is revealed; moving logically in the reverse direction, the transformations of the single texture then reveal the shape of the surface. The problem for the notion of pictorial invariants, however, is that other than texture and similar repeating elements in pictures, the term would seem to be an oxymoron.

\section{Direct and indirect perception}

I claim that Gibson's theories of picture perception were a driving force behind his broader theories. For example, Gibson discussed his concept of direct perception in the context of picture perception (Gibson, 1954b), long before he discussed it in the context of everyday perception (Gibson, 1972, 1973).

Much has been written about direct perception (Cutting, 1986b; Michaels \& Carello, 1981; Uliman, 1979), perhaps too much (Hochberg, 1990 ), so only a capsule summary will be given here. Gibson's earliest theory of picture perception (Gibson, 1954b, p. 3) began with a discussion of "experiencing at first hand" (observing the world) and "experiencing at second hand" (looking at pictures). The first was called direct; the second indirect. The more faithful the picture could be made to reality, the closer the two became. Thus, the more the picture looked like a real segment of the environment the more direct was its perception. Such a statement implies a continuum between the two types of perception.

Gibson (1960b) later gave up on "first- and second-handedness" and on the idea of a continuum between pictures and reality, but he always maintained that pictures were perceived indirectly, reality directly: "Direct perception is what one gets from seeing Niagara Falls, say, as distinguished from seeing a picture of it' (Gibson, 1979, p. 147). Indirect perception was mediated by devices (like cameras and telescopes); direct perception was not (even by glasses). Such a distinction creates confusion and Gibson's followers have debated whether picture perception should be considered direct or indirect (Michaels \& Carello, 1981). 
But as the term direct perception became applied to the perception of the natural environment it came to imply other meanings and created further confusion. Part of the problem with the use of the term direct perception is that Gibson borrowed it from the philosophy of perception without acknowledging its rich 250-year history. Instead, he cited only one source (Austin, 1962). Cutting (1986b) detailed eight different, older meanings of the term, each with a long history. On top of this mélange, Gibson created a new meaning: Direct perception occurred when perceptual information was adequate and specified what could be perceived, which I have discussed earlier.

For my part, Gibson's last theory of picture perception is, to use one of his own favorite expressions, a muddle. He resisted the discussion and use of pictorial cues in perception, which are useful, many, and could even be said to have the power to "specify" what can be perceived; he was later wedded to one-to-one mappings between information and objects seen, embracing singular invariants and further negating the manifold of cues; and he pressed for the theoretical use of invariants in a medium that allowed no change. From his early theories of picture perception he then foisted upon us a term of deep confusion and polysemy, direct perception.

Picture perception is thus a central part of the ecological approach, but also probably its most flawed and has proven least fruitful. Since some central concepts of the ecological approach seem to work least well in the domain of pictures and since some of its more general concepts originated in the pictorial domain, one could legitimately wonder about the integrity of the whole enterprise.

\section{CONCLUSION}

That now obvious rite of passage from global psychophysicist to ecological psychologist produced Gibson's metatheory, a system for appreciating and for thinking about the problems of perception. As a metatheory it has been extremely fruitful where it has been applied, but this fruitfulness cannot hide the incongruities and inconsistencies that remain. We have an appreciation for the role of evolution in shaping our perceptual capacities; we now have a small set of invariants and another cluster of affordances both of which seem sensible and rigorously studied; we can appreciate that perception and action often go together, often elegantly in the context of games or of exploration; and we do distinguish between reality and pictures of reality. However, we do not know how to understand and intermix the biological and cultural ecologies which underlie perception; we do not yet know where the study of affordances will lead 
us; we still have not recognized the costs of studying perception solely in the context of action and exploration; and we need to assess the full utility of perceptual information and the role that invariants, gradients, and other sources of information play.

Acknowledgment. Supported by National Science Foundation Grant DBS 92-12786 to James E. Cutting. This essay is based, in part, on a talk given at a symposium organized by Julian Hochberg entitled "Perceptual theories at the end of the 20th century" given at the 25th International Congress of Psychology in Brussels, July 1992. I thank Nan E. Karwan for her interest, encouragement, instigations and for many discussions of the ideas presented here; and thank Paul Braren, Matthew Cornillon, David Field, James Fu, Beena Khurana, Daniel Levin, Daniel Simons, Peter Vishton for their comments on a draft of this paper.

\section{DISCUSSION}

Sergio C. Masin (Department of General Psychology, University of Padua, Padua, Italy): According to Cutting's fine analysis, J. J. Gibson's ecological approach shows "incongruities and inconsistencies," and one could even "legitimately wonder about the integrity of the whole [Gibson] enterprise" (p. 248). ${ }^{5}$ Cutting's analysis provides the opportunity to examine the possible reasons for the decline of a modern perceptual "metatheory." Although there may be particular reasons why theories or metatheories are destined to fail, it is possible that Gibson's approach shares some common fundamental problem with other past theories or metatheories. I think it would be most interesting and important if some of these problems were elucidated here. To contribute to this discussion I offer my own opinion on this matter.

I think that the basic reason for the decline of Gibson's metatheory is his implicit adoption of the naive-realist view of reality. This view is best illustrated in Gibson's notion of the "optical array," this being the "spherical projection of light to a point." Using Cutting's words, according to Gibson "light coming from any local region of the optical array comes from a single object at a single depth value" (p. 233) and "... most objects

5 Undoubtedly, Gibson greatly contributed to the advancement of perceptual science. For example, he developed the important notion of "invariant," which is central in his approach. However, Gibson's approach seems weak also on this point. Cutting concludes that "The search for invariants has been sufficiently fruitful to warrant continued interest in them, but the results of this search also warrant skepticism about their overall utility" (p. 245). This conclusion is particularly important because it comes from an expert perceptual scientist who devoted "the better part of 15 years" to this search. 
are opaque and because light travels in straight lines, nearer objects often interpose themselves between the observer and the reflected light from farther objects. The layout of surfaces in the optical array then shows abrupt discontinuities where the edge of a nearer object ends and the revealed surface of the farther ubjext begins" (p. 233) (emphasis added).

There are three possibilities: in these statements "light" means (1) something that we see (2) something fictitious (3) the well-known physical concept. Possibility 1 is false because we do not see light traveling "in straight lines." Gibson was too fine an observer to believe that this possibility was true. Possibility 2 means that "light" is something imagined and without any physical effect. Gibson cannot have meant this because he believed that objects may stop light reflected by other objects. Then, it remains that Gibson used "light" in the usual physical sense. But this usage in the above statements implies the belief that seen objects reflect or emit photons. This belief reveals that Gibson implicitly adopted the naive-realist view of reality. There are at least six logical arguments showing that seen objects do not reflect or emit photons (see p. 53, this volume). Therefore, the naive-realist view is wrong.

In my opinion, the naive-realist view of reality should be banncd from perceptual science both because it is wrong and because it has the detrimental effect of diverting the attention of perceptual researchers from the basic objective of their science. In fact, by considering seen objects as entities that reflect light, these objects tend to be (wrongly) considered as entities pertaining to the physical domain and therefore with no need of an explanation on the part of the perceptual scientist. To reiterate, although often governed by physical laws, seen objects do not pertain to the physical domain because in no case do they comprise elementary particles or reflect or emit photons. Thus, contrary to what is implied by the naiverealist view, explaining why and in which conditions seen objects occur is a fundamental objective of perceptual science. I think that a theory or metatheory that distracts from this objective is doomed to failure.

Cutting: Let me make two points in response. First, and more quickly, my analysis questions the coherence of Gibson's metatheory but it does not question its fruitfulness for psychology. Indeed, 1 believe coherence is often overemphasized as a design feature of theories: many physicists doubt the coherence of quantum electrodynamics and many biologists doubt the coherence of nonsaltationist theories of evolution. Nonetheless, the former remains a fruitful basis of prediction for certain microphysical phenomena and the latter a fruitful framework for understanding most of the diversity in life. In a roughly similar vein Gibson's ecological approach has been fruitful, not only because of an emphasis on invariants 
(which Masin acknowledges), but more broadly because of its general emphasis on the study of everyday phenomena and their importance to perception, on the global sources of information which specify objects and events which populate everyday perception, and on its rejection of traditional approaches to perception based on sensation. Moreover, it is not at all clear, as in implied by Masin, that Gibson's metatheory is in decline. Indeed, Hochberg (1990) even describes it as a majority view.

Second, and in much more detail, let me address the important issue of Gibson and naive realism. Russell $(1940$, p. 14) defined naive realism as "the doctrine that things are what they seem;" Köhler (1938, p. 405) defined it as "the identification of percepts with physical things." Both of these definitions seem consistent with Masin's usage. As I understand his argument, Masin's rejection of naive realism is similar to Russell's (1940, p. 15): "Naive realism leads to physics, and physics, if true, shows that naive realism is false. Therefore naive realism, if true, is false; therefore it is false."

Naive realism is usually contrasted with critical realism (or indirect realism), in which care is taken to dissociate the phenomenal world from the physical world. It is often said that in the commerce of negotiating everyday life even the most skeptical scientist is a naive realist-it is most practical to be so-but that in his or her research he or she must be a critical (indirect) realist. I assume Masin (the scientist) is a critical realist and would argue that the "basic objective" of perceptual science is that of traditional psychophysics: We must observe the mappings between the phenomenal and physical worlds. Before Gibson, this was the prototypic epistemological position for a perceptual psychologist.

Gibson tried to forge something new, and with mixed success. Gibson's relationship with naive realism was complex, and is perhaps best captured by Henle (1974), some of whose arguments I will follow. As an introduction, however, let me say that Masin is partly right: Gibson embraced certain aspects of naive realism (Gibson, 1967b), but he also rejected other aspects of it (Gibson, 1971b).

Gibson also rejected critical realism, and the error of "concluding that we can know nothing but our perceptions... Once having made this argument, a theorist is trapped in a circle of subjectivism and is diverted into futile speculations about private worlds" (Gibson, 1959, pp. 462-463n). Instead, Gibson embraced

levels of 'privacy' in perception. All observers can obtain exactly the same information about a tree if they all walk around it and get the same perspectives. Each observer gets a somewhat different set of perspectives of his own hands than any other observer gets, although there is much in common. But the perspective of one's own nose is 
obviously unique and no one else can ever see it from that particular point of view... The tree, the hand, the nose, are increasingly private (Gibson, 1967b, p. 171).

Thus, Gibson maintained that most of perceived world around us is objective and that conspecific perceivers can generally share percepts about that world. But Gibson was not as "naive" a realist as one might think. For example,

One might conceive that the stimulus for motion is simply motion. But this would be a serious misconception... The displacement of a body in space is mapped not as a displacement of a figure in an empty visual field, but as a figural transformation (Gibson, 1966, p. 203).

Thus, phenomenal objects and events can be said to be less closely identified with physical objects and events than they are with the information about those objects and events, and information about their transformations. Such information supports perception, and occasionally it can lie about the true states of physical affairs (Gibson, 1979). But information does not typically lie; instead, it much more typically specifies what should be perceived. Information is generally trustworthy, and thus perception is generally trustworthy.

In keeping with his analyses from the everyday meanings of words, Gibson both embraced, and tried to escape from, naive realism. His approach was to use the following linguistic duality: We perceive objects and events in the physical world around us, but our perceptual systems pick up information about the world in the form of invariants, gradients, and other higher-order variables.

In this manner, and going beyond Henle (1974), one might say that Gibson was a naive realist when talking about the facts of perception, but a critical realist when talking about the basis of perception. Such a stance attempts to preserve the adequacy of everyday language when discussing perception, but also attempts to preserve the scientific enterprise in determining its basis. Gibson $(1972,1979)$ called this position direct realism, in contrast to both naive realism and critical realism. It tries to avoid the patent errors of naive realism, so clearly noted by Masin, and also the encapsulating subjectivism of critical realism. It remains a duality, but it is not a Cartesian duality; it is a duality of discourse. Percepts, objects, and events on the one hand, and information and its pick up on the other, are all objective, but objective at different levels.

In placing Gibson within the fold of naive realism, Masin provided a short analysis of the psychology of light. As possible meanings inherent in Gibson, Masin correctly rejects the ideas that we "see" light (we don't, 
we see objects and events) or that light is "something imagined and without any physical effect" (p. 250). By method of residues, Masin than correctly assumes that Gibson used the concept of light in the standard physical sense. But Masin then argues that this stance "implies the belief that seen objects reflect or emit photons" (p. 250). Such a statement is a Rylean category error: it mixes levels of analysis which Gibson worked hard to separate.

Photons are no more (or less) real than objects and events: they simply exist at a different level of reality. Moreover, psychologists need not try to understand physical objects in terms of photons any more than metereologists need try to understand thunderstorms in terms of electrons, or economists need to understand monetary exchange in terms of the chemical composition of coins and paper, despite the fact that all are equally "real." Seen objects are things we perceive, and exist at one level of discourse with an adequate language to describe them; photons are part of the metaphysical substructure of reality which physics tells us is sufficiently convenient for understanding matter, and exist at a completely different level.

Thus, Gibson would claim that the perceptual psychologist's task is not that of traditional psychophysics. It is not to discern the correspondences between physical dimensions and psychological dimensions (which are traditionally almost always dimensions of sensation). This approach is wrong according to Gibson because perception is not based on sensation. Instead, the perceptual psychologist's task is to understand and to measure the nature of the information in the world which supports perception.

This approach to perception entails two stages in perceptual research, although they are not always equally acknowledged by the followers of Gibson. One must first isolate candidate sources of information which lawfully correspond to a given object or event (always acknowledged in the ecological approach); one must then adequately demonstrate that this candidate information is used in perception (sometimes omitted from researchers based on the ecological approach). The latter is necessary because, as I noted in this chapter, it is not clear that more than one source of information may exist for a given object and event and that information use may be context sensitive. Moreover and more simply, perceptual information is not information unless it is used by perceivers in at least one demonstrable context.

Masin: I feel I have to repond to Cutting on two points. The first is that I did not mix levels of analysis-"a Rylean category error." Cutting attributes an error to me that I impute to Gibson. It is Gibson who mixed 
levels of analysis, not me. The second minor point concerns Cutting's arbitrary assumption that $\mathrm{I}$ am a critical realist. The perceptual approach that I present in this volume rejects all the above mentioned kinds of realism.

Cutting: Ah! One must be careful with any modifications of realism. Espousing realism in the study of perception allows the scientist and philosopher commerce with discussions of, and connections to, biology. It also allows the formulation of an understanding of perceptual solutions to tasks performed in a biologically relevant context. The more the form of one's realism is modified, the more one's discussion of perception becomes removed from both biology and from everyday life.

\section{REFERENCES}

APPELLE, S. (1991). Haptic perception of form: Activity and stimulus attributes. In M. A. Heller \& W. Schiff (Eds.), The psychology of touch (pp. 168-188). Hillsdale, NJ: Erlbaum.

AUSTIN, J. L. (1962). Sense and sensibilia. Oxford: Oxford University Press.

BARAC-CIKOJA, D. \& TURVEY, M. T. (1991). Perceiving aperture size by striking. Journal of Experimental Psychology: Human Perception and Performance, 17, 330-346.

BERGMAN, R. \& GIBSON, J. J. (1959). The negative after-effect of the perception of a surface slanted in the third dimension. American Journal of Psychology, 72, 364-374.

BINGHAM, G. P., SCHMIDT, R. C., \& ROSENBLUM, L. D. (1989). Hefting for a maximum distance throw: A smart perceptual mechanism. Journal of Experimental Psychology: Human Perception and Performance, 15, 507-528.

BOOTSMA, R. J. \& VAN WIERINGEN, P. C. W. (1990). Timing an attacking forehand drive in table tennis. Journal of Experimental Psychology: Human Perception and Performance, 16, 21-29.

BRUNSWIK, E. (1943). Organismic achievement and environmental probability. Psychological Review, 50, 255-272.

BRUNSWIK, E. (1956). Perception and the representative design of psychological experiments. Berkeley, CA: University of California Press.

BURTON, G. \& TURVEY, M. T. (1990). Perceiving the lengths of rods that are held but not wielded. Ecological Psychology, 2, 295-324.

CASSIRER, E. (1944). The concept of group and the theory of perception. Philosophy and Phenomenological Research, 5, 1-35. 
CHAN, T.-C. \& TURVEY, M. T. (1991). Perceiving the vertical distances of surfaces by means of a hand-held probe. Journal of Experimental Psychology: Human Perception and Performance, 17, 347-358.

CUTTING, J. E. (1978a). Generation of synthetic male and female walkers through manipulation of a biomechanical invariant. Perception, $\mathbf{7}$, 393-405.

CUTTING, J. E. (1978b). Perceiving the geometry of age in a human face. Perception \& Psychophysics, 24, 566-568

CUTTING, J. E. (1981). Six tenets for event perception. Cognition, 10, 7178 .

CUTTING, J. E. (1982). Two ecological perspectives: Gibson vs. Shaw and Turvey. American Journal of Psychology, 95, 199-222.

CUTTING, J. E. (1984). Reflections on surfaces: A cross-disciplinary reply to Stevens. Journal of Experimental Psychology: General, 113, 221-224.

CUTTING, J. E. (1986a). Perceiving and recovering structure from events. In N. L. Badler \& J. K. Tsotsos (Eds.), Motion: Representation and perception (pp. 141-147). New York: North Holland.

CUTTING, J. E. (1986b). Perception with an eye for motion. Cambridge, MA: MIT Press/Bradford Books.

CUTTING, J. E. (1987). Rigidity in cinema seen from the front row, side aisle. Journal of Experimental Psychology: Human Perception and Performance, 13, 323-334.

CUTTING, J. E. (1988). Affine distortions of pictorial space: Some predictions for Goldstein (1987) that La Gournerie (1859) might have made. lournal of Experimental Psychology: Human Perception and Performance, 14, 305-311.

CUTTING, J. E. (1991a). Four ways to reject directed perception. Ecological Psychology, 3, 25-34.

CUTTING, J. E. (1991b). On the efficacy of cinema, or what the visual system did not evolve to do. In S. Ellis, M. Kaiser, \& A. Grunwald (Eds.), Pictorial communication in virtual and real environments (pp. 486495). London: Taylor \& Francis.

CUTTING, J. E. (1991c). Why our stimuli look as they do. In G. R. Lockhead \& J. R. Pomerantz (Eds.), Perception of structure: Essays in honor of Wendell R. Garner (pp. 41-52). Washington, DC: American Psychological Association.

CUTIING, J. E. \& MILLARD, R. T. (1984). Three gradients and the perception of flat and curved surfaces. Journal of Experimental Psychology: General, 113, 198-216.

CUTTING, J. E. \& PROFFITT, D. R. (1982). Minimum principle and the perception of absolute, common, and relative motions. Cognitive Psychology, 14, 211-246. 
CUTTING, J. E., PROFFITT, D. R., \& KOZLOWSKI, L. T. (1978). A biomechanical invariant for gait perception. Journal of Experimental Psychology: Human Perception and Performance, 4, 357-372.

CUTTING, J. E., SPRINGER, K., BRAREN, P. A., \& JOHNSON, S. H. (1992). Wayfinding on foot from information in retinal, not optical, flow. Journal of Experimental Psychology: General, 121, 41-72.

DODGE, R. (1907). An experimental study of visual fixation. Psychological Review Monograph Supplements, 8(4), 1-95.

GARNER, W. R. (1962). Uncertainty and structure as psychological concepts. New York: Wiley.

GIBSON, E. J. \& WALK, R. (1960). The visual cliff. Scientific American, 202(4), 64-71.

GIBSON, J. J. (1929). The reproduction of visually perceived forms. Journal of Experimental Psychology, 12, 1-39.

GIBSON, J. J. (1933). Adaptation, after-effect and contrast in the perception of curved lines. Journal of Experimental Psychology, 16, 1-31.

GIBSON, J. J. (1937). Adaptation with negative after-effect. Psychological Review, 20, 553-569.

GIBSON, J. J. (1950a). The implications of learning theory for social psychology. In J. G. Miller (Ed.), Experiments in social process: A symposium on social psychology. New York: McGraw-Hill.

GIBSON, J. J. (1950b). The perception of the visual world. Boston: Houghton-Mifflin.

GIBSON, J. J. (1950c). The perception of visual surfaces. American Journal of Psychology, 63, 367-384.

GIBSON, J. J. (1951). What is a form? Psychological Review, 58, 403-412.

GIBSON, J. J. (1954a). Ordinal structure and the possibility of a global psychophysics. Proceedings of the 14th International Congress of Psychology (pp. 178-179). Amsterdam: North Holland.

GIBSON, J. J. (1954b). A theory of picture perception. Audio-Visual Communication Review, 1, 3-23.

GIBSON, J. J. (1957). Survival in a world of probable objects. Contemporary Psychology, 2, 33-35.

GIBSON, J. J. (1958). Visually controlled locomotion and visual orientation in animals. British Journal of Psychology, 19, 182-194.

GIBSON, J. J. (1959). Perception as a function of stimulation. In S. Koch (Ed.), Psychology: A study of a science (vol. 1, pp. 456-501). New York: McGraw-Hill.

GIBSON, J. J. (1960a). The information contained in light. Acta Psychologica, 27, 23-30.

GIBSON, J. J. (1960b). Pictures, perspective, and perception. Daedalus, 89, 216-227. 
GIBSON, J. J. (1961). Ecological optics. Vision Research, 1, 253-263.

GIBSON, J. J. (1962). Observations on active touch. Psychological Review, $69,477-491$.

GIBSON, J. J. (1965). Constancy and invariance in perception. In G. Kepes (Ed.), The nature and art motion (pp. 60-70). New York: Brazilier.

GIBSON, J. J. (1966). The senses considered as perceptual systems. Boston: Houghton-Mifflin.

GIBSON, J. J. (1967a). James J. Gibson. In E. G. Boring \& G. Lindzey (Eds.). A history of psychology in autobiography (vol. 5, pp. 127-143). New York: Appleton-Century-Crofts.

GIBSON, J. J. (1967b). New reasons for realism. Synthese, 17, 162-172.

GIBSON, J. J. (1970). On theories of visual space perception: A reply to Johansson. Scandinavian Journal of Psychology, 11, 75-79.

GIBSON, J. J. (1971a). The information available in pictures. Leonardo, 4, 27-35.

GIBSON, J. J. (1971b). The legacies of Koffka's Principles. Journal for the History of the Behavioral Sciences, 7, 3-9.

GIBSON, J. J. (1972), A theory of direct visual perception. In J. Royce \& W. Rozeboom (Eds.), Psychology and knowing (pp. 215-240). New York: Gordon \& Breach.

GIBSON, J. J. (1973). Direct visual perception: A reply to Gyr. Psychological Bulletin, 79, 396-397.

GIBSON, J. J. (1978). The ecological approach to the visual perception of pictures. Leonardo, 11, 227-235.

GIBSON, J. J. (1979). The ecological approach to visual perception. Boston: Houghton-Mifflin.

GIBSON, J. J. \& CROOKS, L. E. (1938). A theoretical field analysis of automobile-driving. Americant Journal of Psychology, 51, 453-471.

GIBSON, J. J. \& HUDSON, L. (1935). Bilateral transfer of the conditioned knee-jerk. Journal of Experimental Psychology, 18, 774-783.

GIBSON, J. J. \& KAUSHALL, P. (1973). Reversible and nonreversible events (film). State College, PA: Psychological Cinema Register.

GIBSON, J. J. \& RAFFEL, G. (1936). A technique for investigating retroactive and other inhibitory effects in immediate memory. Journal of General Psychology, 15, 107-116.

HALPERN, B. P. (1983). Tasting and smelling as active, exploratory sensory processes. American Journal of Otolaryngology, 4, 246-249.

HARRE, R. (1981). Great scientific experiments. Oxford: Phaidon Press/Oxford University Press.

HELMHOLTZ, H. v. (1978). The facts of perception. In R. Kahl (Ed. and trans.), Selected writings of Hermann von Helmholtz (pp. 366-407). Middletown, CT: Wesleyan University Press. 
HENLE, M. (1974). On naive realism. In R. B. MacLeod \& H. L. Pick, Jr. (Eds.), Perception: Essay in honor of James J. Gibson (pp. 40-56). Ithaca, NY: Comell University Press.

HILDRETH, E. C. (1992). Recovering heading for visually-guided navigation. Vision Research, 32, 1177-1192.

HOCHBERG, J. (1990). After the revolution. Contemporary Psychology, 35, 750-752.

KOFFKA, K. (1935). Principles of Gestalt psychology. New York: Harcourt.

KÖHLER, W. (1938). The place of values in a world of facts. New York: Liveright.

LEE, D. N. (1980). The optic flow field: The foundation of vision. Philosophical Transactions of the Royal Society of London, B290, 169-179.

LENNEBERG, E. (1962). Understanding language without ability to speak: A case study. Journal of Abnormal and Social Psychology, 65, 419-425.

LEYTON, M. (1992). Symmetry causality mind. Cambridge, MA: MIT Press/Bradford Books.

LIBERMAN, A. M. \& MATTINGLY, I. G. (1985). The motor theory of speech perception revisited. Cognition, 21, 1-36.

MARK, L. S. (1987). Eyeheight-scaled information about affordances: A study of sitting and stair climbing. Journal of Experimental Psychology: Human Perception and Performance, 13, 361-370.

MARR, D. (1981). Vision. San Francisco: Freeman.

MICHAELS, C. F. \& CARELLO, C. (1981). Direct perception. Englewood Cliffs, NJ: Prentice-Hall.

MUNDY, J. L. \& ZISSERMAN, A., (Eds.) (1992). Geometric invariance in computer vision. Cambridge, MA: MIT Press.

NEISSER, U. (1976). Cognition and reality. San Francisco: Freeman.

NIALL, K. K. (1992). Projective invariance and the kinetic depth effect. Acta Psychologica, 81, 127-168.

NIALL, K. K., \& MACNAMARA, J. (1989). Projective invariance and visual shape constancy. Acta Psychologica, 72, 65-79.

NIALL, K. K., \& MACNAMARA, J. (1990). Projective invariance and picture perception. Perception, 19, 637-660.

NORMAN, D. A. (1988). The psychology of everyday things. New York: Basic.

NORMAN, D. A. (1992). Turn signals are the facial expressions of automobiles. Reading, MA: Addison Wesley.

PALMER, S. (1991). Goodness, Gestalt, groups, and Garner: Local symmetry subgroups as a theory of figural goodness. In G. R. Lockhead \& J. R. Pomerantz (Eds.), Perception of structure: Essays in honor of Wendell $R$. 
Garner (pp. 23-40). Washington, DC: American Psychological Association.

PERRONE, J. A. (1992). Model for the computation of self-motion in biological systems. Journal of the Optical Society of America, A, 9, 177194

PITTENGER, J. B. \& SHAW, R. E. (1975). Aging faces as viscal-elastic events: Implications for a theory of non-rigid shape perception. Joumal of Experimental Psychology: Human Perception and Performance, 1, 374-382.

POINCARÉ, H. (1905). Science and hypothesis. Paris: Flammarion. (Reprinted by Dover, 1952.)

POTTER, M. C., KROLL, J., \& HARRIS, C. (1979). Comprehension and memory in rapid sequential reading. In R. Nickerson (Ed.), Attention and Performance VIII (pp. 395-418). Hillsdale, N]: Erlbaum.

PROFFITI, D. R., CUTTING, J. E., \& STIER, D. M. (1979). Perception of wheel-generated motions. Joturnal of Experimental Psychology: Human Perception and Performance, 5, 289-302.

REED, E. S. (1988). James $J$. Gibson and the psychology of perception. New Haven, CT: Yale University Press.

RESTLE, F. (1980). The seer of Ithaca. Contemporary Psychology, 25, 291293.

ROSENBLUM, L. D., SALDAÑA, H. M., \& CARELLO, C. (1993). Dynamical constraints on pictorial action lines. Journal of Experimental Psychology: Human Perception and Performance, 19, in press.

RUSSELL, B. (1940). An inquiry into meaning and truth. New York: Norton.

SAVELSBERG, G. J. P., WHITING, H. T. A., \& BOOTSMA, R. (1992). Grasping tau. Journal of Experimental Psychology: Human Perception and Performance, 17, 315-322.

SHANNON, C. E., \& WEAVER, W. (1949). The mathematical theory of communication. Urbana: University of Illinois Press.

STEVENS, K. N. (1984). On gradients and texture "gradients." Journal of Experimental Psychology: General, 113, 217-220.

STOFFREGEN, T. (1990). Multiple sources of information: For what? Newsletter of the International Society for Ecological Psychology. 4(1), 4-6.

TODD, J. T. \& REICHEL, F. D. (1989). Ordinal properties in the visual perception and cognition of smoothly curved surfaces. Psychological Review, 96, 643-657.

TURVEY, M. T. (1992), Affordance and prospective control: An outline of the ontology. Ecological Psychology, 4, 173-187. 
ULLMAN, S. (1980). Against direction perception. The Behavioral and Brain Sciences, 3, 373-415.

VIVIANI, P. \& STUCCHI, N. (1992). Biological movements look uniform: Evidence of motor perceptual interactions. Joumal of Experimental Psychology: Human Perception and Performance, 18, 603-623.

WARREN, W. H. (1984). Perceiving affordances: Visual guidance of stair climbing. Journal of Experimental Psychology: Human Perception and Performance, 10, 683-703.

WARREN, W. H., MORRIS, M. W., \& KALISH, M. (1988). Perception of translational heading from optical flow. Journal of Experimental Psychology: Human Perception and Performance, 14, 644-660.

WARREN, W. H. \& SHAW, R. E., (Eds.) (1985). Persistence and change. Proceedings of the first international conference on event perception. Hillsdale, N]: Eribaum.

WARREN, W. H., \& WHANG, S. (1987). Visual guidance of walking through apertures. Journal of Experimental Psychology: Human Perception and Performance, 13, 371-383.

WATTS, R. G. \& BAHILL, A. T. (1990). Keep your eye on the ball: The science and folklore of baseball. San Francisco: Freeman. 